\title{
Colorimetry and TV Colour Splitting Systems
}

\author{
J. Kaiser, E. Košt'ál
}

The colorimetric standard of the present-day television system goes back to the American NTSC system from 1953. In this RGB colorimetric system it is not possible, for basic reasons, to produce a scanning device which will provide signals suitable for controlling any displayed unit. From the very beginning of the television system the scanning device has produced inevitable colour deformation. The range of reproductive colours is not fully utilized either by a contemporary Cathode Ray Tube display unit or by a Liquid Crystal Display. In addition, the range is not sufficient for true reproduction of colours. Specific technical and scientific applications in which colour bears a substantial part of the information (cosmic development, medicine) demand high fidelity colour reproduction. The colour splitting system, working in the RGB colorimetric system, continues to be universally used. This article submits the results of a design for a colour splitting system working in the $X Y Z$ colorimetric system (hereafter referred to as the XYZ prism). A way to obtain theoretical spectral reflectances of partial XYZ prism filters is briefly described. These filters are then approximated by real optical interference filters and the geometry of the XYZ prism is established.

Keywords: TV colorimetry, colour splitting system, interferential filters, TV reproduction, colour gamut.

\section{Introduction}

The colorimetry of all present-day TV standards (analog as well as digital) emanates from the original NTSC TV standard. When this TV standard was put forward the cathode ray tube (CRT) was the only available display device. The conventional scanning system (the RGB prism) is characterized by the reproductive lights of the display and by a comparative white light. The existence of negative parts of the colour matching functions $\bar{r}(\lambda), \bar{g}(\lambda), \bar{b}(\lambda)$ causes complications by optical separation of partial pictures $\boldsymbol{R}, \boldsymbol{G}, \boldsymbol{B}$ in the classic scanning system. This leads to distortion in the reproduction of colour images. However, the present-day market offers many kinds of display devices, most notably LCD and plasma displays. These new displays have other, sometimes preferable colorimetric features, but we cannot take advantage of these better features due to dependence on the conventional RGB system [1]. However, the TV camera, which scans in a colorimetric system of unreal lights $\mathbf{X}, \mathbf{Y}, \mathbf{Z}$, is not predetermined by the colorimetric features of any display device. Theoretical spectral reflectances of partial filters of the XYZ prism correspond to the colour matching functions $\bar{x}(\lambda), \bar{y}(\lambda), \bar{z}(\lambda)$, which are only positive [2]. This solves a number of problems that are encountered when realizing the conventional scanning system (RGB prism). A camera working in the XYZ colorimetric system produces electrical analogs of trichromatic components $X, Y, Z$. So every kind of display device has a circuit of colorimetric transformation from the system of lights $\mathbf{X}, \mathbf{Y}, \mathbf{Z}$ into the system of primary (reproductive) lights in the given display device. Another advantage of the XYZ colorimetric system is that one of the scanning channels is directly channel Y. In this case, its noise is identified only by its own scanning device. The two remaining channels (X, Z) carry colour information and just by realizing such a camera we can anticipate lower resolution of details in the $\mathrm{X}$ and $\mathrm{Z}$ channels.

\section{Colorimetric systems - a comparison}

The basis for each colorimetric space is created by three lights. For each colorimetric system, the colour matching functions are defined. These functions are determined by the basic lights and the comparative white light. Each colorimetric system has its chromaticity diagram. This is usually issued from the colorimetric system of unreal lights $\mathbf{X}, \mathbf{Y}, \mathbf{Z}$. As the triangle (in the MKO chromaticity diagram, see Fig. 1), whose vertices create the lights $\mathbf{X}, \mathbf{Y}, \mathbf{Z}$, overlays the whole gamut of existing colours, the colour matching functions $\bar{x}(\lambda), \bar{y}(\lambda), \bar{z}(\lambda)$, are only positive (Fig. 2). The XYZ colorimetric system is the only one with only positive colour matching functions. The $\mathrm{RGB}_{\mathrm{NTSC}}$ colorimetric system has been used in TV since 1953. The lights $\mathbf{R}, \mathbf{G}, \mathbf{B}$ create a triangle, which is inscribed in the gamut of all existing colours, hence the corresponding colour matching functions $\bar{r}(\lambda), \bar{g}(\lambda), \bar{b}(\lambda)$ are bipolar (Fig. 3). Negative parts of these colour matching functions come up to partitions of the area of all existing colours, which lie in the second and the fourth quadrant of the $\mathrm{RGB}_{\mathrm{NTSC}}$ chromaticity diagram (Fig. 4). Mutual conversion among colorimetric systems is conducted by means of the general colorimetric transformation [3].

For correct scanning of colour information, the three channels of the TV camera scanning set must have sensitivities equal to some colour matching functions. It is apparent that only positive sensitivities can be realized optically. The reason for this is fundamental. There is no negative radiation intensity, there is no negative medium transparency and the photoeffect is also a response of the output quantity (charge, current, voltage) only to the radiation intensity. Hence the real sensitivities of the RGB prism channels follow at the very most only the positive parts of the ideal sensitivities (Fig. 4). Colour information about the scanning scene is in this way knowingly neglected ahead of the optical-electrical conversion on the image sensors. The end effect of incorrect scanning is reduced fidelity of colour reproduction on a display unit and also on the CRT from which the channel sensitivities of the RGB prism are derived.

The summing curve of any colour matching functions embodies the characteristic minimum at a wavelength of around $500 \mathrm{~nm}$. The summing curve of colour matching functions $\bar{x}(\lambda), \bar{y}(\lambda), \bar{z}(\lambda)$ and $\bar{r}(\lambda), \bar{g}(\lambda), \bar{b}(\lambda)$ is shown in Fig. 5 . It is interesting that, for evaluating colour, human vision does not use information that is contained at a wavelength of around $500 \mathrm{~nm}$. 


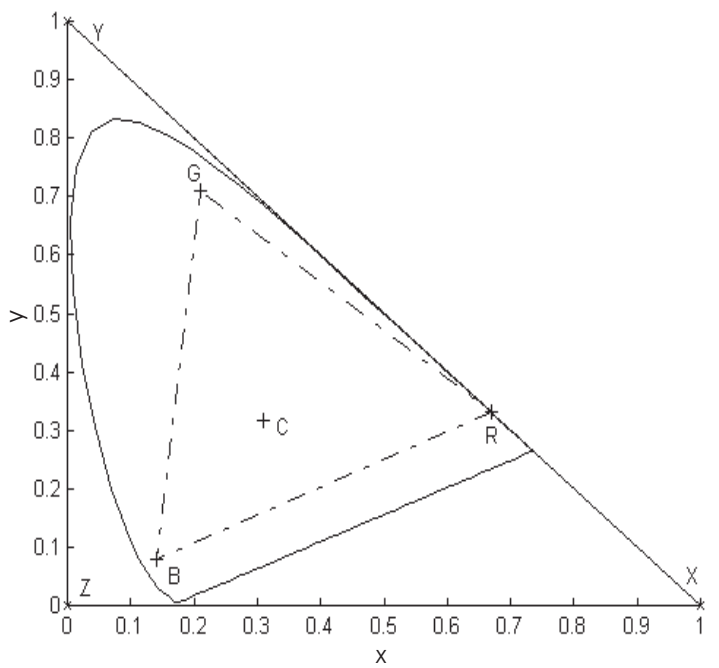

Fig. 1: MKO chromaticity diagram with lights $\mathbf{X}, \mathbf{Y}, \mathbf{Z}$ and $(\mathbf{R}, \mathbf{G}, \mathbf{B})_{\mathrm{NTSC}}$

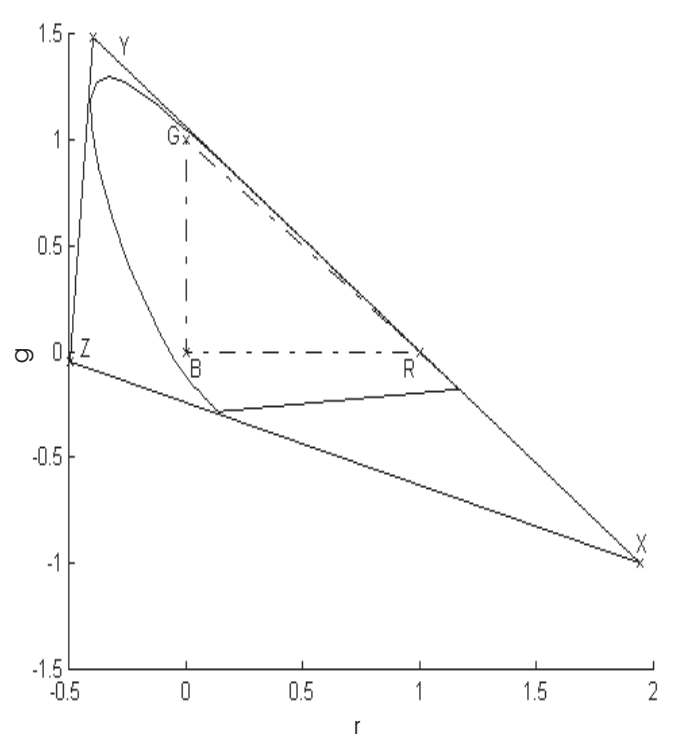

Fig. 3: $\mathrm{RGB}_{\mathrm{NTSC}}$ chromaticity diagram with lights $\mathbf{X}, \mathbf{Y}, \mathbf{Z}$ and $(\mathbf{R}, \mathbf{G}, \mathbf{B})_{\mathrm{NTSC}}$

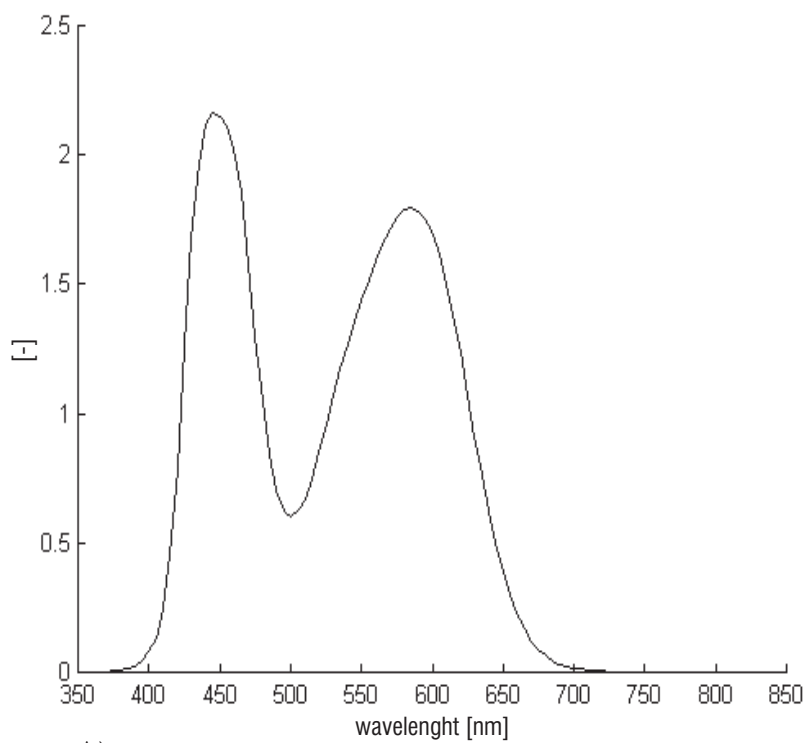

A)

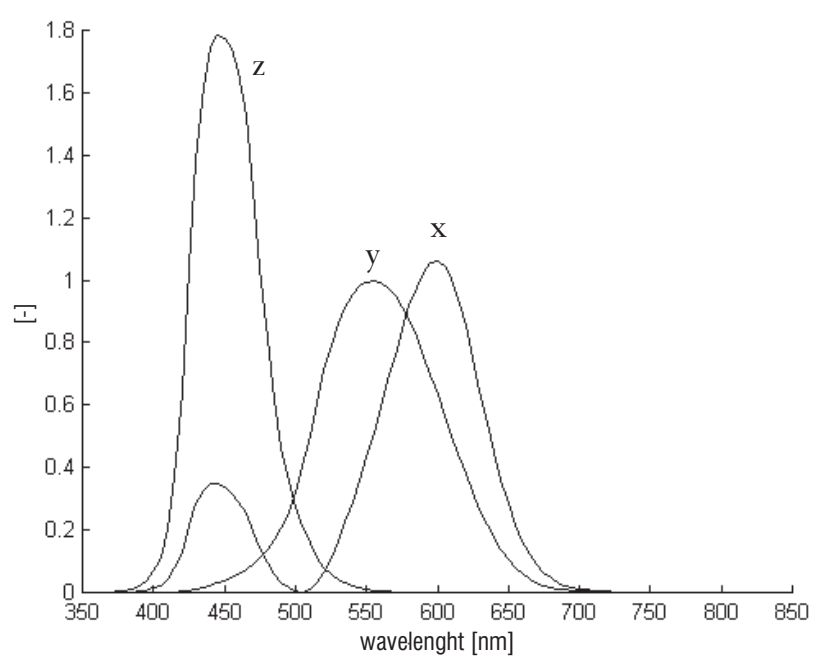

Fig. 2: Colour matching functions $\bar{x}(\lambda), \bar{y}(\lambda), \bar{z}(\lambda)$

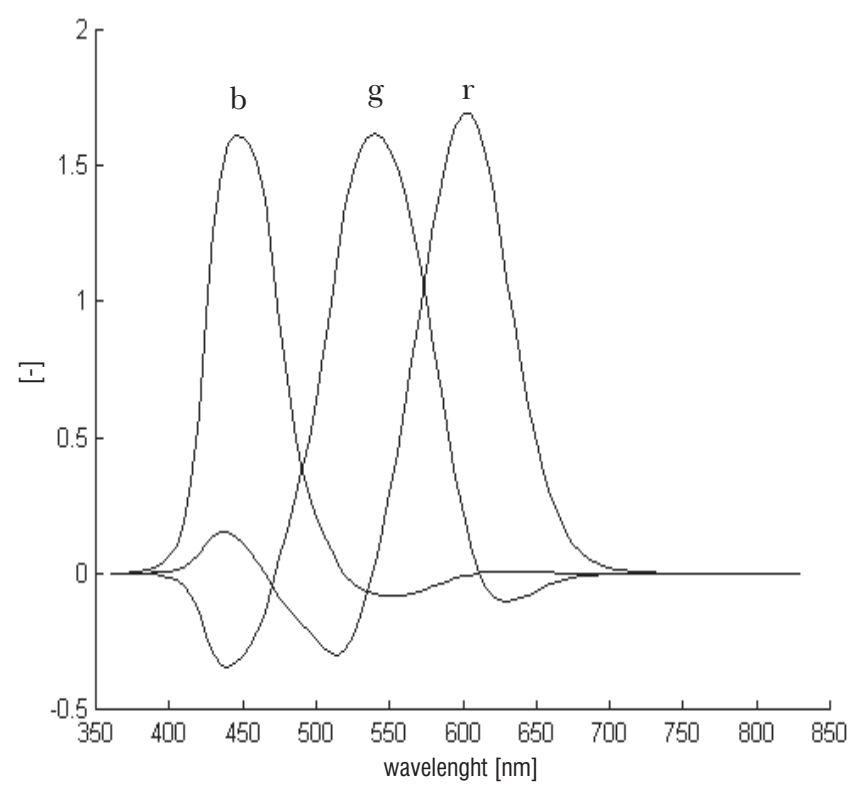

Fig. 4: Colour matching functions $\bar{r}(\lambda), \bar{g}(\lambda), \bar{b}(\lambda)$

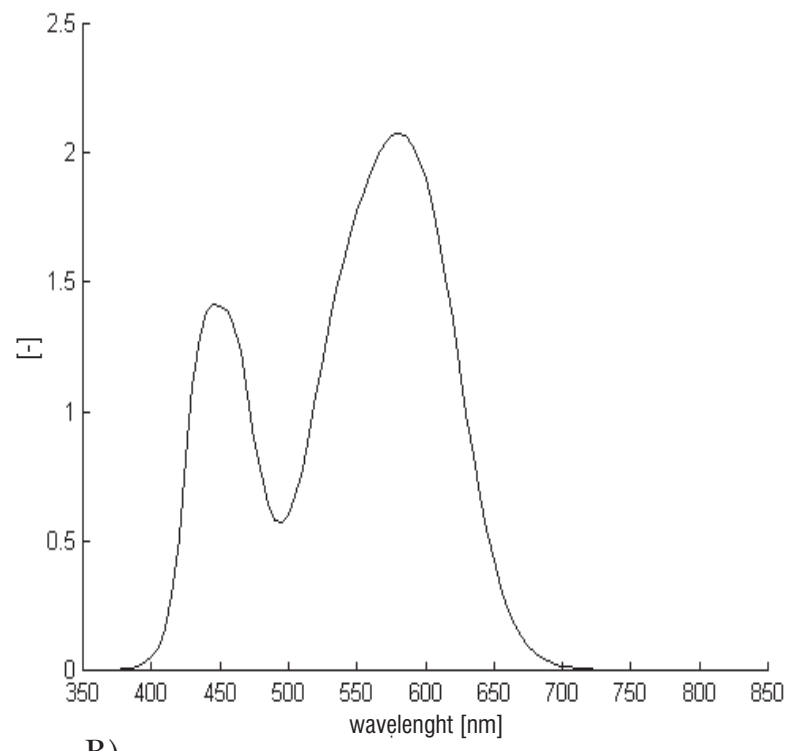

B)

Fig. 5: Summing curve of colour matching functions $\bar{x}(\lambda), \bar{y}(\lambda), \bar{z}(\lambda)(\mathrm{A})$ and $\bar{r}(\lambda), \bar{g}(\lambda), \bar{b}(\lambda)(\mathrm{B})$ 


\section{Spectral reflectances of partial filters of the XYZ prism}

On the basis of Fig. 6, a system of three equations for spectral sensitivities of partial channels $\bar{x}^{\prime}(\lambda), \bar{y}^{\prime}(\lambda), \bar{z}^{\prime}(\lambda)$ of the proposed scanning system can be compiled. The spectral reflectances of partial filters $\mathbf{A y}(\lambda), \mathbf{B x}(\lambda)$, and $\mathbf{C z}(\lambda)$ are unknown [4].

$$
\begin{aligned}
& \bar{y}^{\prime}(\lambda)=\mathbf{A y}(\lambda) \\
& \bar{x}^{\prime}(\lambda)=\mathbf{B x}(\lambda)(1-\mathbf{A y}(\lambda)) \\
& \bar{z}^{\prime}(\lambda)=\mathbf{C z}(\lambda)(1-\mathbf{A y}(\lambda))(1-\mathbf{B x}(\lambda))
\end{aligned}
$$

The spectral sensitivities of partial channels $\bar{x}^{\prime}(\lambda), \bar{y}^{\prime}(\lambda)$, $\bar{z}^{\prime}(\lambda)$ of the proposed scanning system are the colour matching functions $\bar{x}(\lambda), \bar{y}(\lambda), \bar{z}(\lambda)$ (CIE 1931, 2-deg), which are corrected for maximum efficiency of transmission of light flux through the colour splitting system, also for maximum transparence of the splitting system, and for the spectral sensitivities of image sensor CCD.

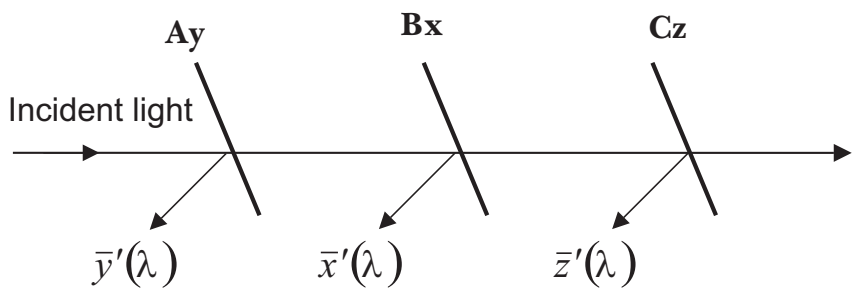

Fig. 6: The sequence of separation of partial components (images)

With the solution of equations (1), (2), (3), we acquire spectral reflectances of partial filters $\mathbf{A y}(\lambda), \mathbf{B x}(\lambda)$ and $\mathbf{C z}(\lambda)$. The solutions show that the colour splitting system is not orthogonal. It turns out that the curves of the spectral sensitivities of the scanning system overlap one another above the wavelength axis. By separation, the light energy is sucked into two and in some places even into three paths. The ideal spectral reflectances of the partial filters of the XYZ prism are

$$
\begin{aligned}
& \operatorname{Ay}(\lambda)=\bar{y}^{\prime}(\lambda) \\
& \mathbf{B x}(\lambda)=\bar{x}^{\prime}(\lambda) /\left(1-\bar{y}^{\prime}(\lambda)\right) \\
& \mathbf{C z}(\lambda)=\bar{z}^{\prime}(\lambda) /\left(1-\bar{y}^{\prime}(\lambda)-\bar{x}^{\prime}(\lambda)\right) .
\end{aligned}
$$

The approximations of ideal spectral reflectances $\mathbf{A y}(\lambda)$, $\mathbf{B x}(\lambda), \mathbf{C z}(\lambda)$ by real optical interference filters (see Fig. 7) were made using the Synopsys programme [5]. The technical solution of real optical interference filters involves producing dichroic thicknesses [6], [7], [8]. These form a coating of a shiny pellucid medium (e.g., boro-silicate glass BK7) with thicknesses comparable with the wavelength of light. The thicknesses are sorted step by step with the alternating higher and lower refractive index. Filter $\mathbf{A y}(\lambda)$ is built up from eight layers of three materials $\left(\mathrm{MgF}_{2}, \mathrm{CeF}_{3}, \mathrm{CeO}_{2}\right)$, filter $\mathbf{B x}(\lambda)$ is built up from twelve layers of four materials $\left(\mathrm{MgF}_{2}, \mathrm{CeF}_{3}\right.$, $\left.\mathrm{CeO}_{2}, \mathrm{SiO}\right)$, and filter $\mathbf{C z}(\lambda)$ has twelve layers of three materials $\left(\mathrm{MgF}_{2}, \mathrm{CeF}_{3}, \mathrm{ZrO}_{2}\right)$ [11].
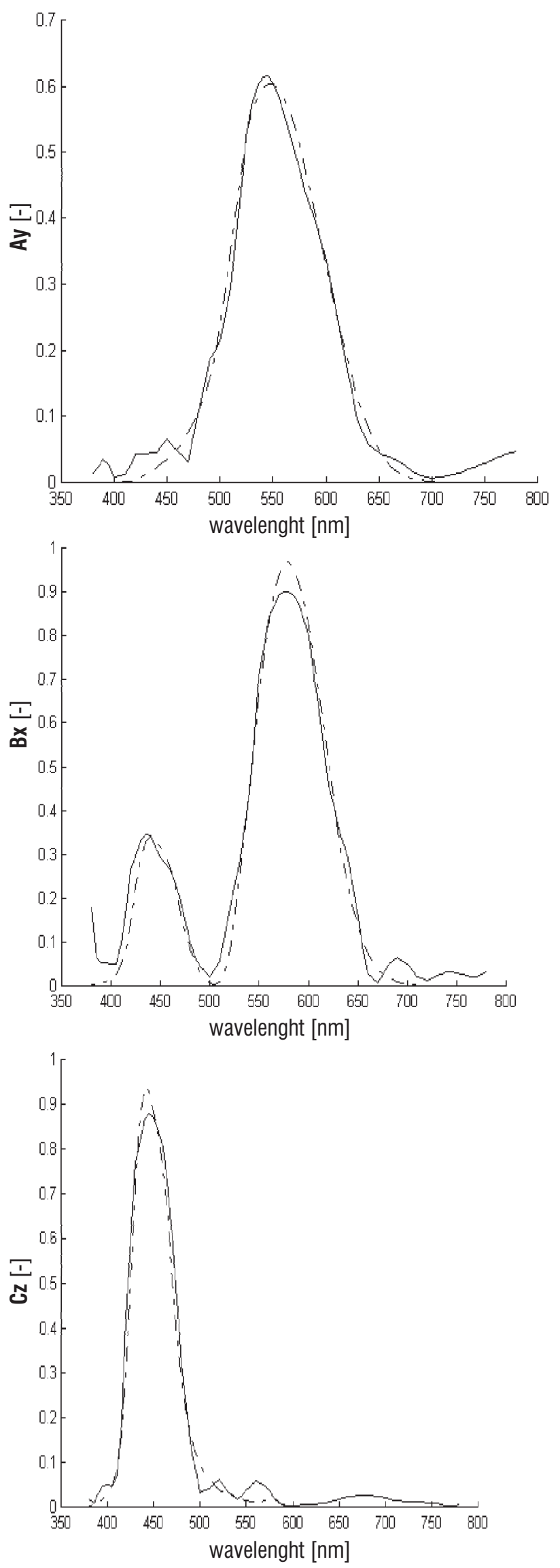

Fig. 7: Ideal spectral reflectances $\mathbf{A y}(\lambda), \mathbf{B x}(\lambda), \mathbf{C z}(\lambda)$ and their approximation byreal optical interference filters (approximation by real filters - full line) 


\section{Geometry of the XYZ colour splitting system}

The XYZ colour splitting system (see Fig. 8) consists of four prisms and three interference filters. The colour splitting system constitutes a three-band frequency selective switch of light pencils and a three-band amplitude switch. The pencils generate the partial images $\boldsymbol{X}, \boldsymbol{Y}, \boldsymbol{Z}$ on the outputs of the switch. The images are scanned via three sensors, e.g., CCD sensors, and video signals $\mathrm{E}_{\mathrm{X}}, \mathrm{E}_{\mathrm{Y}}, \mathrm{E}_{\mathrm{Z}}$ are obtained as electrical analogs of the trichromatic components $X, Y, Z$. The prism is made of BK7 glass. The third prism functions only as an adjusting shim to provide sufficient room for image sensor $\boldsymbol{Z}$. Each of the prisms is proposed and sorted in set so that the trace lengths of the partial light tubes will be identical and the proportions of the prisms will enable trouble-free transit of light tubes of the required diameter. All three filters are reflective-interferential. The rear surfaces of the first, second and fourth prism are coated with these filters, i.e., in the direction in which the beams are going. The third prism creates an adjusting shim. The filters are built up of dielectric multilayers of the following materials: $\mathrm{SiO}, \mathrm{MgF}_{2}, \mathrm{CeF}_{3}$, $\mathrm{ZrO}_{2}, \mathrm{CeO}_{2}$. The spectral reflectances of partial filters $\mathbf{A y}(\lambda)$, $\mathbf{B x}(\lambda), \mathbf{C z}(\lambda)$ are illustrated in Fig. 2. Each partial light tube executes two reflections in the XYZ prism. The first reflections of the partial light tubes occur on filters $\mathbf{A y}(\lambda), \mathbf{B x}(\lambda)$ and $\mathbf{C} \mathbf{z}(\lambda)$. These reflections are frequency and amplitude selective. The second reflections of the light tubes are total and occur on the front walls (on the glass-air passages) of the first, second and fourth prism. After the second reflections, the partial light tubes with spectral sensitivities $\bar{y}^{\prime}(\lambda), \bar{x}^{\prime}(\lambda)$ and $\bar{z}^{\prime}(\lambda)$, respectively, come to the image sensors.

Due to the transmissivity of the XYZ prism, and due to the summing curve of the spectral sensitivities $\bar{x}^{\prime}(\lambda)+\bar{y}^{\prime}(\lambda)+\bar{z}^{\prime}(\lambda)$, only a part of the incident light spectrum is used to obtain the trichromatic components $X, Y, Z$ (partial images $\boldsymbol{X}, \boldsymbol{Y}, \boldsymbol{Z}$ ). The unused light spectrum, mainly the section around wavelength $500 \mathrm{~nm}$, passes through filter $\mathbf{C z}(\lambda)$ and leaves the XYZ prism. This light must be absorbed in the camera (e.g., absorption with velvet) to prevent it being reflected back into the prism. Otherwise this light would cause spurious artefacts in the picture during reproduction.

In order to create glass-air passages, i.e., total reflections also for components $X$ and $Z$, there has to be a slim air interspace $0.1-0.2 \mathrm{~mm}$ in thickness between each two prisms. This air interspace is also needed between the second and the third prism. It does not engender total reflection, but the air interspace has a favourable effect on the number of layers and on the kinds of filter material $\mathbf{B x}(\lambda)$. In other words, the impedance match of the filters will be less demanding if there is a substance with different impedance on all sides of the filter.

\section{Conclusion}

This paper aims to show how the colorimetry of the TV scanning set could proceed to full exploitation of the new range of colorimetric display devices. The $X Y Z$ colour splitting system encounters no insuperable difficulties during optical separation of partial components (which are found in the classic RGB scanning system). Its ideal spectral sensitivities are, in contrast to the ideal spectral sensitivities of the clas-

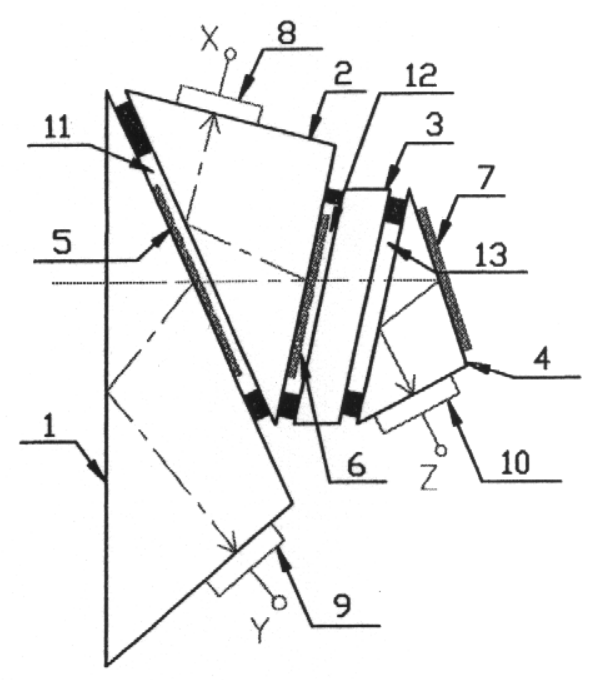

Fig. 8: The XYZ colour splitting system (1, 2, 3, 4- glass prisms; 5, 6, 7 -dielectric multilayers (filters); 8, 9, 10-image sensors; 11, 12, 13 - air interspaces)

sic scanning system, only positive. Hence, there is no longer any need to introduce additional corrections for areas with negative spectral sensitivities of partial channels. All three filters in the XYZ prism are of the reflective-interferential type, unlike the green filter of the RGB prism, which is coloured and therefore absorptive. The colorimetric system of primary lights $\mathbf{X}, \mathbf{Y}, \mathbf{Z}$ overlays the whole gamut of existing colours. For light of any colour, the trichromatic components $X, Y, Z$ are only positive. The end effect is that the colour gamut of reproduction will not be reduced [10], [11].

\section{Footnote}

The XYZ colour splitting system for TV cameras was submitted by doc. Ing. Emil Koštál, CSc., Ing. Jan Kaiser and Ing. Jiří Slavík as a utility model and patent application [12]. A registration certificate for the utility model was granted on 29. 5. 2000. The number of the utility model is 10026 . The certificate of patent registration was granted on 19. 4. 2001. Number of the patent is 288456 .

\section{References}

[1] Koštál, E.: Obrazová a televizní technika II - Televize (Image and television technology II - TV). Učební text ČVUT 1998, p. 135

[2] http://cvision.ucsd.edu/index.html, CIE Standards, Color spectra databases

[3] Ptáček, M.: Přenosové soustavy barevné a digitálni televize (Transmission systems of colour and digital TV). 2. vydání, Nadas Praha 1981, p. 488

[4] Slavík, J.: Návrh světlodělící soustavy pro kameru pracujicí v kolorimetrickém systému $X, Y, Z$ (Design of colour splitting system for TV camera working in the $X, Y, Z$ colorimetric system). Unpublished manuscript, 1999

[5] http://www.GWI.net/OSD, Synopsys program

[6] Dobrowolski, J. A.: Completely Automatic Synthesis of Optical Thin Film Systems. Applied Optics, Vol. 4, No. 8, Aug. 1965, p. 937 
[7] Ditchburn, R. W.: Light. $3^{\text {rd }}$ Edition, Acad. Press, 1976

[8] Novák, Z.: Optické soustavy snimacích zařízení (Optical set of scanning devices). Učební text pro postgraduální studium, ČVUT 1971

[9] Pazderák, J.: Kolorimetrie snímacích soustav barevné televize a elektronické kolorimetrické korekce (Colorimetry of scanning systems of colour TV and electronic colorimetric corrections). Edice CS. TELEVIZE, řada II, svazek 16, Praha 1974, p. 150

[10] Svoboda, V.: Kolorimetrie a zdokonalené televizní soustavy (Colorimetry and improved TV systems). In: Televize 94 č.1, IVP ČT Praha 1994, pp. 65-114

[11] Kaiser, J.: Kolorimetrie zdokonalených TV soustav (Colorimetry of improved $T V$ systems). Diploma project, ČVUT 2001

[12] Koštál, E., Kaiser, J., Slavík, J.: Hranolová světlodělicí soustava pro televizni kamery (The colour splitting system for
TV cameras). Přihláška vynálezu (patent application) č. PV 2000-1167, 30. 3. 2000

Ing. Jan Kaiser

e-mail: xkaiserj@feld.cvut.cz

Department of Radioelectronics

Czech Technical University in Prague

Faculty of Electrical Engineering

Technická 2, 16627 Praha 6, Czech Republic

Doc. Ing. Emil Košt’ál, CSc.

e-mail: kostalem@worldonline.dk

Ryvangs Allé 14

2100 Copenhagen 0

Czech Embassy, Dánsko 